WellBeing International

WBI Studies Repository

7-1977

\title{
Mammalian Dispersal and the Ontogeny of Individual Behavioral Phenotypes
}

Marc Bekoff

University of Colorado

Follow this and additional works at: https://www.wellbeingintlstudiesrepository.org/acwp_ena

Part of the Animal Studies Commons, Environmental Studies Commons, and the Population Biology Commons

\section{Recommended Citation}

Bekoff, M. (1977). Mammalian dispersal and the ontogeny of individual behavioral phenotypes. American Naturalist, 715-732.

This material is brought to you for free and open access by WellBeing International. It has been accepted for inclusion by an authorized administrator of the WBI Studies Repository. For more information, please contact wbisr-info@wellbeingintl.org.

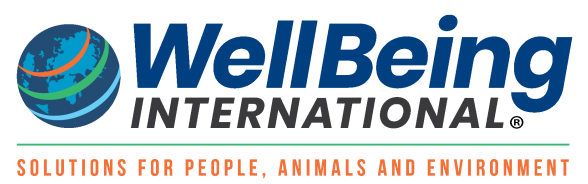




\title{
Mammalian Dispersal and the Ontogeny of Individual Behavioral Phenotypes
}

\author{
Marc Bekoff \\ University of Colorado
}

The dispersal of young and old animals is a topic of wide interest. However, behavioral mechanisms underlying dispersal still are relatively unknown, particularly the relationships among behavioral development, agonistic behavior, and dispersal. Our lack of knowledge about behavioral causes of dispersal is unfortunate, since this information could be extremely useful in helping to answer theoretical questions about such timely topics as sib competition and parent-offspring conflict (Alexander 1974; Trivers 1974; Wilson 1975; Barash 1977; Bekoff 1977a). As Gadgil (1971, p. 253) has written, "Dispersal is one of the most important and amongst the least understood factors of population biology." With the appearance of recent data on a variety of mammalian species, it is becoming clear that "universal" hypotheses about dispersal based on single underlying mechanisms may have limited applicability. This paper will review briefly two of the more "visible" theories of mammalian dispersal and then present a hypothesis that is consistent with recent observations on a variety of mammals, and more important, one that is testable using observable behavioral patterns as its raw data. It considers the ontogeny of individual behavioral phenotypes and its relationship to later individual dispersal patterns. Inferential data supporting the hypothesis are available, particularly for members of the family Canidae, with parallels in various species of marmots (Sciuridae).

It is usually assumed that dispersal allows each individual to maximize its own chance to reproduce (Lidicker 1962; Murray 1967). For juvenile individuals prior to their first mating, dispersal may be defined as the movement of an individual from its natal site and out of the home range of its parent(s) to another site at which it breeds, or at least attempts to pair with a conspecific of the opposite sex for purposes of breeding. Short-term exploratory movements or changes in the boundaries of a home range are not included (Lidicker 1975). For an adult individual the term "dispersal" usually refers to movements away from its own (or group) home range to another area. The length, and direction, of movements vary from species to species and from individual to individual and, in themselves, do not distinguish dispersal from some other types of movements.

At this point, it is important to stress that the term "dispersal" has been used both to describe the emigration of individuals of species (particularly rodents) that experience somewhat regular population cycles (e.g., microtine cycles) as well as movements of individual (usually juvenile) animals in the absence of such cycles. However, as will be discussed below, the behavioral mechanisms may be different in each of the two cases.

\section{DISPERSAL, AGGRESSION, AND DOMINANCE}

In 1970, Christian summarized available literature and suggested that there was a direct correlation between aggressive behavior and dispersal, especially in various voles (Microtus spp.). According to this hypothesis, low-ranking, subordinate individuals (predominantly juveniles) are forced to disperse into suboptimal habitats by being aggressively driven out by more dominant individuals. The rare subordinate migrant that survives in the new habitat provides the raw material for evolution. 
Supporting data for Christian's (1970) hypothesis come from studies on a variety of small mammals such as woodchucks (Marmota monax), deermice (Peromyscus man,iculatus), yellow-pine chipmunks (Eutamias amoenus), and ground squirrels (Spermophilus columbianus and S. undulatus) (see Bronson 1964; Healey 1967; Broad brooks 1970; Steiner 1972). However, there is an equal number of exceptions to the aggression-dispersal hypothesis, and, in a wide variety of mammals, the relationship between agression and dominance and that among aggression, dominance, and dispersal are not at all clear cut (Archer 1970; Bernstein 1970; King 1973; Rowell 1974; Barnett 1975; Preston 1975; Lockwood 1976). That is, aggressive individuals are not necessarily the most dominant, and dominant individuals are frequently less agressive than the individuals they dominate.

Data contrary to the aggression-dispersal hypothesis stem particularly from field studies conducted on animals that do not undergo somewhat regular population cycles, such as red foxes (Vulpes vulpes; Vincent 1958; Allison 1971; Storm 1972; Storm and Montgomery 1975; Storm et al. 1976), Richardson's ground squirrels (Spermophilus richardsonii; Yeaton 1972; Michener 1973), and yellow-bellied marmots (Marmota fiaviventris; Armitage 1973, 1974). However, even among cyclic microtines, there are exceptions (Krebs et al. 1973; Rose and Gaines 1976). None of these workers found support for the idea that juvenile dispersal directly results from socially dominant individuals driving out more subordinate individuals through overt aggression. In fact, in red foxes, marmots, and captive coyotes (Canislatrans), there is a strong tendency for individuals to avoid one another and to show increasing independence just prior to the time of dispersal, with no increase in any type of social contact. Yeaton (1972, p. 145) concluded for the Richardson's ground squirrels he observed that "dispersal must be caused by factors other than those environmental or behavioral factors that were present or apparent."

Although high levels of aggression may characterize the social environment both before and during dispersal in some mammals, it is clear that there is not a unidirectional process that results in the subordinate (less aggressive?) individuals being driven out. In fact, very aggressive prairie dogs (Oynomys ludovicianus) may leave their coterie of their own accord rather than driving out other prairie dogs (King 1955). Highly aggressive house mice (Mus musculus domesticus; Busser et al. 197 4) and female yellow-bellied marmots (Downhower 1968, cited by Svensden 1974) may also disperse. In addition, Krebs et al. (1973) noted that male Microtus pennsylvanicus that dispersed during peak populations tended to be even more aggressive (more dominant?) than residents in control areas. Thus, although there may be a continuum of aggressiveness and/or dominance-subordinate relationships, it is essential to emphasize that either of the "types" may emigrate.

\section{DISPERSAL AND GENOTYPES}

Considerable attention is being focused upon the genetics of individual dispersal (e.g., Andrewartha and Birch 1954; Howard 1960; Chitty 1967; Myers and Krebs 1971, 1974; Krebs et al. 1973; Hilborn 1975; Wilson 1975). Howard (1960) stressed that there was a strong innate predisposition for some individuals to disperse. He wrote that the individuals that innately disperse are predisposed at birth to disperse beyond the confines of their parent's home range, and that these individuals possess a dispersal "instinct." To avoid circular thought, it is necessary both to demonstrate genetic differences between dispersers and nondispersers and to show that these genetic differences are causally related to dispersal. Nothing at all is gained by saying that individuals that disperse do so because they are possessed with a dispersal instinct. Substantiated predictions of dispersal versus nondispersal in individuals differing only in genotype would provide acceptable data. Such data have not been collected, although Myers and Krebs (1971, 1974) and Krebs et al. (1973) have analyzed the population cycles in Microtus spp., looking specifically for changes in the genetic composition of a population during a cycle. 
Krebs et al. (1973) believe that intrinsic behavioral factors (the effect of one individual on another) are more important than extrinsic factors (food supply, predators, or disease) in explaining dispersal during rodent population cycles. Following Chitty's (1967) earlier suggestions that the genetic composition of a population might change during a cycle in numbers, they hypothesized that there would be genetic differences between dispersing and nondispersing microtines. Their results indicated that certain genotypes did show a tendency to disperse, a finding consistent with Chitty's hypothesis but not necessarily directly supporting Howard's (1960) idea of innate predispositions for dispersal (a dispersal instinct for individuals), because individual life histories of their animals were unknown. Also, cause and effect could not be untangled (Krebs et al. 1973; Myers and Krebs 1974; Wilson 1975), and no components of fitness have been associated with the various genotypes (Myers and Krebs 1974). As yet, there are no genetic analyses on species in which juveniles (or adults) disperse independent of cyclic population changes.

\section{BEHAVIORAL DEVELOPMENT IN CANIDS AND SOME PARALLELS IN MARMOTS}

Many data have been collected concerning social development in members of the family Canidae, especially for the gray wolf (C. lupus) and coyote, and it is on these two species that I wish to concentrate. The two show very distinct and significantly different trends in behavioral development that are correlated with later species-typical social organization. Adult coyotes are less social than pack-living wolves, although there may be a few exceptions (see below). Very striking parallels have been found in various members of the genus Marmota (see Barash 1974a for review). My major concern will be to relate trends in individual early behavioral development with the later behavior of juveniles in nonsocial and social species. The social environment in which an individual develops and the "typical" adult social structure in which the individual must later function appear to be closely related (Crook 1974). One factor that has not been studied systematically as playing a possible role in whether or not an individual eventually disperses is, in fact, the experiential history of the individual itself. In general, there is a dearth of information about the true nature of dispersing individuals (Bertram 1973; Rose and Gaines 1976). In their study of golden jackals (C. aureus), Golani and Keller (1975) have demonstrated the importance of understanding the behavior of individuals, and Armitage (1973) and Svensden and Armitage (1973), studying population dynamics in marmots, likewise have stressed the necessity of determining behavior profiles for identified individual animals.

Coyotes and wolves may be differentiated behaviorally as early as 3-4 weeks of age (Bekoff 1974a; Bekoff et al. 1975), coyotes being significantly more aggressive and less playful than similarly reared wolves of the same age. Between the third and fifth week of life, coyotes typically engage in serious fights, the result of which is a social hierarchy with distinct dominant-subordinate relationships (Bekoff 1977b). Social play is rarely observed before the intense aggressive interactions. In contrast, wolves do not show such an early ontogeny of rank-related aggression, although young wolves occasionally will fight (Mech 1970; Zimen 1975), especially over food (Zimen 1975). Social play is the major form of social interaction in young wolves. Results consistent with these trends have been obtained from coyote and wolf litters reared in a wide variety of situations (Bekoff 1974b; Zimen 1975) and do not appear to be related to differences in physical development (Bekoff and Jamieson 1975). In addition, observations on the social development of the golden jackal $(\mathrm{H}$. van Lawick-Goodall and J. van Lawick-Goodall1970; Wandrey 1975) and the red fox (personal observations), a solitary canid, have shown that these species follow a time course similar to that of the coyote in the development of aggression, while developmental data for various gregarious domestic dogs (C. familiaris) place them closer to wolves with respect to behavioral ontogeny. In fact, infant red foxes are more aggressive than coyotes and less social as adults, and pack-type dogs such as the beagle are even less aggressive than wolves. A striking relationship emerges from comparative developmental studies on canids, namely, that the more social canids fight 
less and play more very early in life than do the less social canids. The early ontogeny of social play and a delay in the appearance of rank-related aggression may be responsible for the development of strong social bonds and of a coordinated social group (Mech 1970; Barash 1974a; Zimen 1975; Bekoff 1977c).

Canids are not the only group of animals in which there is a relationship between the ontogeny of aggression and later species-typical social organization. For example, the highly social Olympic marmot (M. olympus), when compared to the less social yellow-bellied marmot and the least social woodchuck, shows a delay in the appearance of aggressive behavior during ontogeny (Barash 1974a, 1974b). And, as would be predicted from the relationship between behavioral development and adult social organization seen in canids, the yellow-bellied marmot shows a greater delay in the appearance of aggression than does the solitary woodchuck. Therefore, solitary woodchucks resemble solitary red foxes, whereas yellow-bellied marmots and Olympic marmots are more similar to coyotes and wolves, respectively. Although dispersal of young animals is typical of all three marmot species, the development of aggression is related to the age at which they disperse-woodchucks typically disperse at weaning, yellow-bellied marmots at approximately 1 year of age, and Olympic marmots at approximately 2 years of age. In addition, and perhaps of greater significance for the present comparison, for both marmots and canids there is not a consistent relationship between the amount of aggression at the time of dispersal and dispersal. Therefore, the relationships between behavioral development and age of dispersal in herbivorous marmots (see Barash [1974a] for a discussion of possible underlying environmental causes), combined with the fact that aggression is not necessarily a direct cause of dispersal, strongly suggest that the behavioral antecedents of dispersal should be considered and that predispersal individual behavioral profiles be compiled (see also Wilson 1973). Furthermore, because not all individuals in a population necessarily disperse (see below), species profiles, while yielding very interesting general trends, must be supplemented by detailed behavioral profiles on individual animals.

\section{INDIVIDUAL DIFFERENCES AND THEIR POSSIBLE RELATIONSHIP TO DISPERSAL}

In order to gain a better understanding of social dynamics within litters of young animals and how individual differences in behavioral development (differences in genotype?) may be related to, and predictive of, later behavior, it is necessary to perform detailed observations in a longitudinal design. By gathering data on individuals, it also will be possible to characterize each species as to the range of intralitter individual differences.

Individual differences in behavior have been documented widely. Indeed, variability appears to be the rule rather than the exception. In canids, large individual differences during early life have been documented in various foxes, wolves, coyotes, domestic dogs, and golden jackals. Because individual differences in behavioral development are strikingly apparent in animals that exist in very diverse types of social organization, it is important first to ask whether or not there are species differences in the range of intralitter individual differences and, second, whether these differences, if any, may help to explain adult social organization.

Fox (1972, elaborated in Fox [1975]) first attempted to answer this question. Based on earlier observations of the development of behavior in wolves, he hypothesized that the intralitter individual differences he observed would enhance the formation of pack-type social organization in this species, while the supposed lack of such a spectrum of behavioral phenotypes in the less social species would tend to favor group dispersal. In a variety of tests (e.g., prey killing, reactions to novel stimuli) performed on individual wolves comprising four litters, Fox demonstrated that, indeed, there were individual differences amongst the littermates. However, two very important points concerning this interesting study must be mentioned. First, the young wolves were only observed between 7 ! and 9 weeks of age, not a sufficient amount of time to warrant the conclusion that individual variations and differences enhance 
pack formation (Fox 1972, p. 310), and, second, equivalent tests were not performed on any of the less social canids, so interspecific comparisons concerning the range of individual differences or behavioral phenotypes could not be supported adequately. Recently, two litters of coyotes have been tested for individual differences using some of Fox's procedures (specifically prey killing and reactions to novel stationary and moving stimuli) and scoring method (Bekoff, unpub. data). Variances were calculated both for the four litters of wolves with which Fox worked and for the similar data collected on the two coyote litters. The variances for all of the groups of wolves were smaller (range $=2.50-5.62$ ) than either of the two variances calculated for the coyotes $(9.47,8.78)$ but there were no significant differences between any of the six groups ( $P>.05$, F-maximum test for homogeneity of independent variances).

Although these results do not support Fox's hypothesis, the possibility still remains that intralitter individual differences determined using different measures may be related to later social organization. The relationship mentioned above concerning the differential development of aggressive behavior both in canids and marmots displaying different degrees of sociality suggested that, at least at the level of the species, one could correlate different trends in behavioral ontogeny with different species-typical organizational patterns. More detailed analyses of the ways in which individuals interact with one another might generate more useful data than individual reactions to prey or novel objects. The specific question is: What is the range of individual differences, based on patterns of social interaction, in individual litters of species that later show different degrees of sociality? Quantitative data collected both for coyotes and wolves, and qualitative observations of other canids, strongly suggest that the range of individual differences in the early behavioral ontogeny of littermates may be related to later species-typical social organization.

Mech (1970) has postulated that almost all regular members of most wolf packs are related to one another, wolf packs being formed from related family members. A delay in the appearance of potentially divisive aggression, combined with high frequencies of intralitter social play, could increase the likelihood of wolf littermates remaining together (and mating with one another; Mech 1970, p. 53). In contrast, in coyotes (and also red foxes), the early appearance of rank-related aggression before the occurrence of social play might be expected to result in weaker ties between littermates. As Scott and Fuller (1965) and others have demonstrated, the third through approximately the eighth week of life is the period in which canids form both intraspecific and interspecific relations, and long-term effects can be shown in animals undergoing different ontogenetic courses. Accordingly, an attempt was made to determine the effect, if any, of the development of early rank-order relations on intralitter social encounters in coyotes. Specifically, we questioned whether or not an individual's rank affected the way in which it interacted with littermates and, in turn, how littermates interacted with it. Specific behavioral patterns correlated with rank are very common in a wide variety of mammals (Ewer 1968; Jolly 1972; Kruuk 1972; Schaller 1972; Wilson 1975).

The data summarized below have been found consistently in coyote litters that have been either hand reared, mother reared, observed in pairs, or observed as a full litter under seminatural conditions, and we believe that, because of this consistency, similar behavior patterns occur in natural populations. (Given the difficulty of observing young mammals in the field due to lack of visibility or interactions occurring in a den [Schaller 1972; Barash 197 4b; Bekoff 197 4b], large amounts of data on captive subjects are frequently used to make inferences about what is occurring in nature.) Coyote pups typically do not engage in social play with littermates until after a social hierarchy is established. By calculating the success with which each animal in a pair or litter was able to solicit play (see Bekoff 1974a for details) either from its single partner or from other littermates, significant rank-related differences were detected. In coyote pairs, the more dominant individual was less successful in soliciting play than was its more subordinate partner (Bekoff 1974a) and in a full litter the same relationship was found. The correlation 
(Spearman's rho) between an individual's social rank and its success in soliciting social play from another littermate equaled -.79 (table 1). The highest-ranking individual was least successful in soliciting play while lower-ranking littermates were more successful. Analyses of pair-wise interactions in the intact litter showed that the highest-ranking individual was most successful with the two lower-ranking animals and that the middle-ranking individuals were least successful with the most dominant individual. The middleranking individuals played more among themselves (as in wolves; Lockwood 1976). Furthermore, as the animals matured, the most dominant individuals became increasingly unsuccessful at soliciting play and spent more time away from the group. When individual activity patterns and interindividual spatial relations were analyzed (see Bekoff and Corcocan [1975] for the method used), it was observed that, as the highest-ranking individual(s) became increasingly active, other littermates avoided him by moving further away (Bekoff 1977c).

TABLE 1. Success in soliciting play by individual coyote littermates (Successful play solicits/Total number of play solicits

\begin{tabular}{|lccc|}
\hline Social Rank * & Successful Play Solicits & Unsuccessful Play Solicits & Success (\%) $\dagger$ \\
\hline 1 (male) & 13 & 21 & 38.2 \\
2 (female) & 10 & 10 & 50.0 \\
3 (male) & 9 & 10 & 47.4 \\
4 (male) & 20 & 22 & 47.6 \\
5 (male) & 13 & 10 & 56.5 \\
6 (female) & 2 & 1 & 66.7 \\
\hline
\end{tabular}

NOTE. The highest-ranking male attempted to solicit play more frequently than did four of his littermates, and the lowest ranking female was virtually noninteractive (see text).

* Mother reared; results are from approximately $100 \mathrm{~h}$ of observation between 35 and 50 days of age; in this litter, severe dominance fights beginning on day 28 resulted in a linear hierarchy by day 35 (confirmed using Landau's measure of linearity; Chase 1974; Lockwood 1976; Bekoff 1977b). Although linearity occurs quite frequently in coyote litters (Bekoff 1977b), even in situations when nonlinearity is the case, "top" and "bottom" individuals are clearly distinguishable.

† Spearman's rho $=-.79$ (correlation between rank and success). From days 52-70, the success rate of one male fell to $17 \%$, a decrease of $21.2 \%$. The success rates of all of the other animals also fell during this time period (female 6 did not attempt to solicit play at all), but not greater than $9 \%$ in any case. Excluding female 6 still results in a negative correlation between rank and success.

In addition to these findings, I have consistently observed that, within each litter of coyotes studied to date, there was a very subordinate individual (e.g., female 6, table 1) who actively avoided interacting with littermates. These individuals also tend to be behaviorally asynchronous with the rest of their litter (Bekoff 1977c). (Similar observations have been reported for golden jackals [H. van Lawick-Goodall and J. van Lawick-Goodall1970] and wolves [Lockwood 1976; Zimen 1976].) When the social hierarchy was being established (approximately between 4 and 5 weeks of age), this female was aggressively dominated by all other littermates, but soon after, the most dominant male became less aggressive than its lower-ranking sibs, and showed the least amount of aggression towards the most subordinate female. And, as mentioned above, the most dominant individual was most successful in interacting with the two lower-ranking animals. A similar trend has been observed in red foxes (Burrows 1968), for whom it has been suggested that a strong social bond may develop between the top and bottom animal. (It is interesting to note that there are data that indicate that high- and low-ranking animals [chickens and squirrel monkeys] are physiologically more similar to one another than they are to middle-ranking individuals [Candland et al. 1969, 1970].) 
Neither of these trends (the relationships between rank and social interaction patterns and between rank and avoidance patterns) have been observed in infant wolves (Zimen 1976), and, in fact, there appears to be less overall variability between individuals in wolf litters in the early ontogeny of aggressive behavior (Bekoff 1974a, unpublished data; Zimen 1975, 1976).

For the sake of completeness, it is very important to consider both the role of the parent(s) and other adults in facilitating dispersal of their own, or other, young as well as possible underlying physiological mechanisms. The few data available for captive coyotes indicate that parents do not interact very much with their young after weaning for purposes other than feeding (Bekoff 1977b), and that at the time (ca. 69 months of age) at which some individuals would be expected to disperse, the parents do not actively force their young away (Bekoff 1977b), even when the female comes into heat. Field data on red foxes (Allison 1971; Storm 1972), Richardson's ground squirrels (Yeaton 1972; Michener 1973), marmots (Armitage 1974), and other mammals (Harper 1970) indicate that "parental encouragement" to leave the natal site is not necessary to produce dispersal of the young. In fact, the young animals may affect the movement patterns of their parents (Harper 1970, pp. 92-93).

Very little is known about the physiological causes of dispersal. The onset of dispersal by juveniles frequently coincides with the attainment of sexual maturity by the young. In coyotes (and in most other canids for which data are available) both males and females are physiologically capable of breeding during their first year of life (Bekoff 1976). Whether or not there is a common physiological explanation for (1) the variations in the type of behavioral interactions in which an individual participates during early life, (2) the tendency for an individual to leave its sib group (explore its environment and eventually wander off), and (3) the attainment of sexual maturity is not known. Likewise, whether or not early experience (e.g., being a subordinate individual; see Krebs et al. 1976; Sohn 1977) could affect sexual maturity such that a brief delay would render an individual unable to reproduce during its first year of life remains to be studied. For male domestic chickens at least (Andrew 1972a, 1972b), an increase in testosterone levels produces a number of behavioral changes, particularly increased behavioral persistence (e.g., when searching for food) and sexual behavior. Andrew (1972a) has suggested that the effect of testosterone on persistence may produce global changes in behavior and that such changes, if they were to appear in males at the onset of breeding, might make it more likely for them to be successful in acquiring and retaining a breeding site, attracting a mate, and acquiring other important resources. Data for females are lacking. Furthermore, the possibility remains that changes in the composition of urine (and glandular secretions?) coincident with changes in reproductive condition might be important in controlling spatial relations among animals. Scent marking appears to be important in controlling spatial relations in a wide variety of animals (Montgomery 1974 ; Mykytowycz 1974; Peters and Mech 1975).

\section{AN ATTEMPT AT A SYNTHESIS}

The data presented above for canids and marmots suggest that information concerning the social experiential history of individual animals may be a useful predictor of (1) species differences in social organization and (2) which individuals, in a species characterized by dispersal of juveniles, may be most likely to leave their group first. Other data indicate that aggression does not directly lead to dispersal, that aggression and dominance are not necessarily related, and that aggressive as well as dominant individuals may disperse.

As red foxes mature they tend to avoid both littermates and adults and spend more and more time exploring their environment, eventually not returning to their birthplace (Allison 1971; Storm 1972). Avoidance of interaction also is characteristic of captive coyotes and free-living marmots (Armitage 1974). For red foxes and possibly for coyotes and some yellow-bellied marmots, dispersal appears to be a "passive" process; the individuals emigrate not because they are forcibly ejected, but rather they leave of 
their own accord (although aggression can facilitate the process in some instances). Unfortunately, there are no field data relating individual differences in early ontogeny and later dispersal. However, extensive data collected on captive coyotes (and also wolves; Lockwood 1976; Zimen 1976) strongly suggest that some individuals might be more prone to leave their groups than others. In particular, those individuals who have interacted the least with their littermates would have the weakest tics to the group, and it would be predicted that these individuals would be the most likely to disperse (fig. 1). Thus, for coyotes, it would be predicted that the highest- and lowest-ranking individuals within a litter, who have interacted the least with littermates, would be the most likely to leave their group. The only field data that support this hypothesis are from qualitative observations on two canids. Vander Merwe (1953) wrote that in blackbacked jackals (C. mesomelas), the lowest- and the highest-ranking animals were the most likely to disperse and that pair bonds and mate preferences are already established at the time of dispersal. A similar suggestion has been offered for red foxes in England (Burrows 1968). Our coyote data are consistent with van der Merwe's and Burrows's findings. Recurrent "behavioral types" have been observed in a large number of litters, and the way in which littermates interact with one another is highly predictable. (Perhaps the repeatedly observed spectrum of individual differences in different species is responsible for the conservation of social structure from generation to generation; see Crook [1970].) It is currently impossible to conclude whether the genetic differences between individuals comprising a litter are responsible for individual differences in age, distance, or pattern of dispersal. Indeed, predictive data concerning genotypes and dispersal are lacking, and in one study of the relationship between genotype and exploratory behavior in mice ( $P$. polionotus) no significant correlation was found (Blackwell and Ramsey 1972.)

Last, it has been observed that not all coyotes disperse during their first year (Bekoff 1976) and "packs" of coyotes have been observed (Dobie 1961; Camenzind 1975, 1977, personal communication). In most cases it is not known whether these coyote groups are composed of related individuals as has been suggested for wolves. More important, there are no data that show that packs of coyotes function in a highly coordinated fashion as do wolf packs. In the absence of data it would be pure speculation to assume that ecological factors solely are responsible for allowing large numbers of coyotes to live together. For rodents experiencing population cycles (Krebs et al. 1973) and red foxes that do not experience such cycles (Storm 1972), density-dependent environmental factors do not appear to be of primary importance in "causing" dispersal (see also Carroll and Getz 1976; McClenaghan and Gaines 1976). In wolves, it has been suggested that social factors are very important in regulating pack size (Mech 1970; see also Kleiman and Eisenberg 1973; Zimen 1976). In addition to atypical pack-type coyotes, there still are the "lone wolves," for whom behavioral processes underlying dispersal are unknown (Peters and Mech 1975; Lockwood 1976; Zimen 1976), and the only social cat, the lion, with which to contend. Comparative developmental data on felids, as well as developmental behavioral profiles of dispersing versus nondispersing individuals, would provide valuable information. The final analysis, must, of course, account for how individual behavioral types interact with their environment and also the flexibility of the organization under study (Goss-Custard et al. 1972). 
Fig. 1.--A hypothetical relationship between the development of rank-related agonistic behavior, the later appearance of social play, two types of avoidance, the formation of social bonds, and dispersal ("leave group"). "Avoidance by individuals" refers to situations in which some individuals are avoided by sibs; "avoidance of individuals" refers to situations in which some individuals avoid interacting with sibs. Both patterns of avoidance appear to be related to rank in infant and juvenile coyotes (Bekoff 1977c). It is suggested that the formation of distinct dominant-subordinate relationships as a result of early agonistic interactions before the occurrence of social play will result in rank-related individual differences in patterns of social interaction with littermates. Either pattern of avoidance will lead to decreased (in some cases almost none) social interaction and weak social bonds between noninteractive individuals and the rest of their litter (the same argument could apply to many social groups of animals). Those individuals who are weakly tied to their litter (group) will disperse. Those individuals who engage in cohesive interactions with one another will be more likely to remain together for longer periods of time and there would be a delay in dispersal, or dispersal may not occur. For social mammals such as wolves, the appearance of social play before the occurrence of rank-related agonistic behavior may be responsible for the development and maintenance of a coordinated pack from which juvenile dispersal is rare. In this model, the temporal relationship between the ontogeny of rank-related agonistic behavior and social play is stressed as arc the cumulative effects of early experience with littermates.

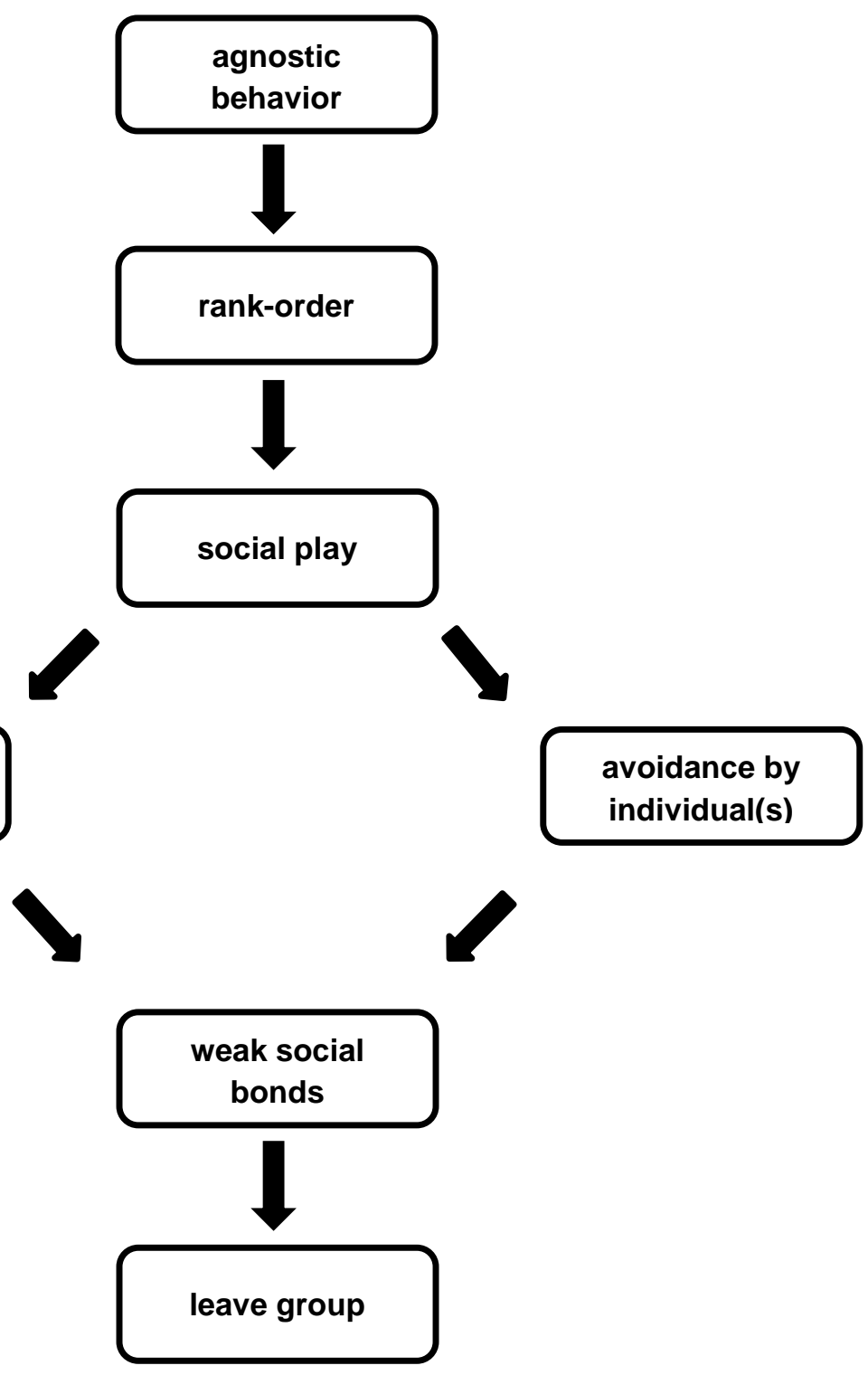

avoidance of individual(s) 


\section{BEHAVIORAL POLYMORPHISM AND DISPERSAL STRATEGY}

Early dispersal of individual animals may be advantageous both for the parents and the young that first emigrate. Those individuals that leave their litter at or around the attainment of sexual maturity may be increasing the probability of successfully mating as soon as they are physiologically able (maximizing their reproductive output) by avoiding competition and/or interference in courtship and mating either by sibs or adults. If individuals of the opposite sex leave together, then the likelihood that they will breed with one another is probably greater than if they depart separately. (As mentioned above, inbreeding probably occurs at high frequencies within wolf packs. For seasonal breeders such as canids, and in particular for the less social species, the best strategy may be to breed with any conspecific of the opposite sex.) If, on the other hand, the two individuals leave independently, there is the possibility that they will breed with unrelated individuals, thus increasing gene flow through outbreeding. However, mortality among young animals between birth and 1 year of age often is very high, and, in addition, mortality may be still higher among younger dispersers (Kozakiewicz 1976; see Wind berg and Keith 1976, pp. 2078-2079). For example, yearling yellow-bellied marmots dispersing long distances may suffer higher mortality than those individuals who move only a short distance or remain in their colonies (Svensden 1974). (For some species, dispersing individuals in general appear to suffer higher mortality, but emigration provides the only opportunity for reproduction [Uinta ground squirrels; Slade and Balph 1974].)

Those individuals that show a delay in dispersing until at least after their first potential breeding season (the possibility remains that they attain sexual maturity later than dispersing individuals; age of maturity may vary within populations [Bell1976]) may have an advantage in that they will be older and more experienced and have a higher survivorship. In addition, they may breed more successfully than early dispersers (especially those that disperse singly) because they have developed closer ties to one another that would facilitate breeding among themselves. Later dispersers could, in fact, stand an equal chance of matching their earlier dispersing sibs in reproductive output.

Thus, opposing selective forces could result in a behavioral polymorphism for age at dispersal. Busser et al. (1974) suggest that this might occur in mice, with aggressive individuals dispersing earliest. In many cases, a mixed strategy of dispersal could be the most advantageous strategy (Gadgil 1971; see also Johnston [1961] for a discussion of behavioral polymorphisms and dispersal distances in song sparrows [Melospiza melodia] and van der Pijl [1969] for a review of analogous mixed strategies of dispersal in plants). It is suggested in this paper that the spectrum of behavioral phenotypes within canid litters has a genetic (polygenic) basis (Bekoff et al. 1975) and that if the range of individual differences during early social ontogeny is large, the execution of the strategies of dispersal mentioned above will be facilitated. In the absence of a wide range of individual differences in social behavior early in life, the evolution of greater sociality will be favored.

\section{CONCLUSIONS}

The most obvious conclusion is that more data are needed for both the behavior of individual animals and the behavioral mechanisms underlying dispersal. A test of the hypothesis developed here requires that data on individual differences be collected during early ontogeny because the hypothesis stresses the importance of the behavioral antecedents of dispersal. The major points can be summarized as follows:

1. Aggression does not necessarily provide the adequate stimulus for dispersal in many mammals.

2. Intralitter individual differences in the behavioral development of coyotes affect the way in which certain individuals interact with their littermates, and also the way in which their siblings interact with them in turn. 
3. Those individuals who have the most difficulty in initiating interactions with their sibs, and others who do not interact for other reasons (most usually because they simply avoid interaction), will not develop strong ties to their group and will be the most likely individuals to leave their natal site first. Other sibs, who have interacted more with one another, will show a delay in dispersing until their first potential reproductive season.

4. Those individuals who disperse as soon as they are physiologically able to reproduce stand a greater chance of maximizing their reproductive output than do late dispersers; however, higher mortality at an early age may be an opposing selective force. Also, a subordinate disperser may not be sexually mature.

5. Opposing selective forces could result in a behavioral polymorphism for dispersal strategies. The range of individual behavioral phenotypes within litters either will facilitate the execution of a mixed strategy of dispersal or will favor the evolution of greater sociality.

In canids and marmots, interspecific differences in behavioral development are highly correlated either with species-typical social organization or age at dispersal, respectively. In canids, intralitter individual differences may be correlated with the fate of individual littermates. The hypothesis presented above relating behavioral development to later social organization has strong inferential support and lends itself to empirical testing.

\section{SUMMARY}

Explanations of dispersal mechanisms in mammals that have stressed the importance of aggression by dominant (?) individuals as the immediate cause of the dispersal of less aggressive (more subordinate?) individuals are insufficient for explaining recent data collected on a variety of mammals. In fact, avoidance of social interaction at the time of dispersal is more characteristic of some species in which individuals emigrate. Studies that have investigated genetic correlates of dispersal in rodent populations that undergo regular cycles are few and have not provided any "causative" explanations. In various canids and rodents, behavioral interactions at the time of dispersal do not appear to provide the necessary stimuli for dispersal. These observations suggest that knowledge of the behavioral interactions that occur before dispersal may provide a key to understanding both interspecific and intraspecific differences in social organization and dispersal patterns. It is suggested that individuals who have the most difficulty interacting with littermates will not develop strong social ties with their siblings and will be the most likely individuals to disperse of their own accord. This hypothesis is testable by collecting data on the social interaction patterns of individual littermates throughout early development and during dispersal. In this way, the importance of a heretofore neglected factor in dispersal-namely, the relationship between the behavioral antecedents of dispersal and which individuals disperse at what age, and in what manner--can be assessed.

\section{ACKNOWLEDGMENTS}

I would like to thank the following people both for critically reviewing an earlier draft of this paper and for discussing many of the issues raised herein: David M. Armstrong, David P. Barash, David Chiszar, Judy Diamond, R. D. Guthrie, B. Holt, Richard E. Jones, Sandra Knight, Charles J. Krebs, Roger Peters, Sharon Pfeifer, Gerry Storm, and two anonymous referees. Anne Bekoff, Joel Berger, Carl Bock, Harriet Hill, and Peter Stacey were of great help in ironing out some rougher edges and to them I am especially grateful. Dorothea Slater kindly typed the manuscript. I, of course, am responsible for any omissions and shortcomings. The research reported in this paper was supported in part by Public Health Service grants GM-01900 and ES-00139 (through Washington University, St. Louis) and a faculty research initiation fellowship and a biomedical support grant from the University of Colorado. 


\section{ADDENDUM}

After this paper was submitted for publication, data were presented by Knight (1976) which showed that, in some cases, dominance hierarchies in captive coyote litters may change at around 5-6 months. I have also observed rank changes in some coyote litters; however, the changes in dominance rank were not accompanied by changes in interaction patterns among all individuals. That is, not all of the animals in a litter (group) necessarily respond to changes that occur between two individuals. In one litter, the firstand second-ranking individuals showed a reversal of dominance at approximately $4 \frac{1}{2}$ months of age. Nonetheless the remaining four animals continued to interact with these two individuals as if nothing had occurred. In some primates, a change in rank does not necessarily change mating, grooming, or other aspects of social relationships (I. Bernstein, personal communication).

\section{LITERATURE CITED}

Alexander, R. D. 1974. The evolution of social behavior. Annu. Rev. Ecol. Syst. 5:325-383.

Allison, L. 1971. Activity and behavior of red foxes in Central Alaska. Master's thesis. University of Toronto. $92 \mathrm{pp}$.

Andrew, R. J. 1972a. Recognition processes and behavior, with special reference to effects of testosterone on persistence. Advance. Stud. Behav. 4: 17 5-208.

---. 1972b. Changes in social behavior in male and female chicks, following different doses of testosterone. Anim. Behav. 20:741-750.

Andrewartha, H. G., and L. C. Birch. 1954. The distribution and abundance of animals. University of Chicago Press, Chicago. 782 pp.

Archer, J. 1970. Effects of population density on behaviour in rodents. Pages 169-210 in J. H. Crook, ed. Social behaviour in birds and mammals. Academic Press, New York.

Armitage, K. B. 1973. Population changes and social behavior following colonization by the yellow-bellied marmot. J. Mammal. 54: 842-854.

1974. Male behaviour and territoriality in the yellow-bellied marmot. J. Zool. London 172:233-265.

Barash, D. P. 1974a. The evolution of marmot societies: a general theory. Science 185: 415-420.

1974b. Mother-infant relations in captive woodchucks (Mannota monax). Anim. Behav. 22:446-448.

1977. Sociobiology and behavior. American Elsevier, New York. 378 pp.

Barnett, S. A. 1975. The rat: a study in behavior. University of Chicago Press, Chicago. 318 pp.

Bekoff, M. 1974a. Social play and play-soliciting by infant canids. Amer. Zoo!. 14:323-340.

---. 1974b. Social play in coyotes, wolves, and dogs. BioScience 24:225-230.

---. 1976. Oanislatra.ns Say. Mammal. Species 79:1-9.

---. 1977a. The evolution of cooperative social behavior and its relationship to conflicts of interest and the communication of misinformation (forthcoming).

---. 1977b. Social development in coyotes and eastern coyotes. In M. Bekoff, ed. Coyote biology: evolution, behavior, ecology, and management. Academic Press, New York (in press).

1977c. Social development, social bonding, and dispersal in canids: the significance of species and individual differences in behavioral ontogeny. Paper presented at the IVth International Conference on the World's Cats and Sociobiology of Carnivores, Seattle.

1977d. Quantitative studies of three areas of classical ethology: social dominance, behavioral taxonomy, and behavioral variability. In B. A. Hazlett, ed. Quantitative methods in the study of animal behavior. Academic Press, New York (in press).

Bekoff, M., and J. Corcoran. 1975. A method for the analysis of activity and spatial relations in animal groups. Behav. Res. Method Instrumentation 7:569.

Bekoff, M., H. L. Hill, and J. B. Mitton. 1975. Behavioral taxonomy in canids by discriminant function analyses. Science 190:1223-1225. 
Bekoff, M., and R. Jamieson. 1975. Physical development in coyotes (Canis latrans) with a comparison to other canids. J. Mammal. 54:685-692.

Bell, G. 1976. On breeding more than once. Amer. Natur. 110:57-77.

Bernstein, I. S. 1970. Primate status hierarchies. Pages 71-109 in L. Rosenblum, ed. Primate behavior. Vol. 1. Academic Press, New York.

Bertram, B. C. R. 1973. Lion population regulation. East Afr. Wildlife J. 11:215-225.

Blackwell, T. L., and P. R. Ramsey. 1972. Exploration activity and lack of genotypic correlates in Peromyscus polionotus. J. Mammal. 53:401-403.

Broadbrooks, H. E. 1970. Home ranges and territorial behavior of the yellow-pine chipmunk, Eutamins amoenus. J. Mammal. 51:310-326.

Bronson, F. H. 1964. Agonistic behavior in woodchucks. Anim. Behav. 12:470-478.

Burrows, R. 1968. Wild fox. Taplinger, New York. 202 pp.

Busser, J., A. Zweep, and G. A. van Oortmerssen. 1974. Variability in the aggressive behaviour in Mus musculus domesticus, its possible role in population structure.

Pages 185-199 in J. H. F. van Abeelen, ed. The genetics of behaviour. American Elsevier, New York.

Camenzind, F. 1975. Territorial and social behavior of free-ranging coyotes. Coyote Res. Newsletter 3:16.

---. 1977. Behavioral ecology of coyotes on the national elk refuge, Jackson, Wyoming. In M. Bekoff, ed. Coyote biology: evolution, behavior, ecology, and management. Academic Press, New York (in press).

Candland, D. K., D. C. Bryan, B. L. Nazar, K. J. Kopf, and M. Sendor. 1970. Squirrel monkey heart rate during formation of status order. J. Comp. Physiol. Psychol. 70:417-423.

Candland, D. K., D. B. Taylor, L. Drisdale, J. M. Leiphart, and S. P. Solow. 1969. Heart rate, aggression, and dominance in the domestic chicken. J. Comp. Physiol. Psycho!. 67:70-76.

Carroll, D., and L. L. Getz. 1976. Runway use and population density in Microtus ochrogaster. J. Mammal. 57:772-776.

Chase, I. D. 1974. Models of hierarchy formation in animal societies. Behav. Sci. 19: 374-382.

Chitty, D. 1967. The natural selection of self-regulatory behaviour in animal populations. Proc. Ecol. Soc. Australia 2:51-78.

Christian, J. J. 1970. Social subordination, population density, and mammalian evolution. Science 168:8490.

Crook, J. H. 1970. The socio-ecology of primates. Pages 103-166 in J. H. Crook, eel. Social behaviour in birds and mammals. Academic Press, New York.

---. 1974. Social organization and the developmental environment. Pages 142-152 in N. F. White, et al. Ethology and psychiatry. University of Toronto Press, Toronto.

Dobie, J. F. 1961. The voice of the coyote. University of Nebraska Press, Nebraska. 386 pp.

Ewer, R. F. 1968. Ethology of mammals. Plenum, New York. 418 pp.

Fox, M. W. 1972. Socio-ecological implications of individual differences in wolf litters: a developmental and evolutionary perspective. Behaviour 41:298-313.

---. 1975. Evolution of social behavior in canids. Pages 429-460 in M. vV. Fox, eel. The wild canids. Van Nostrand Reinhold, New York.

Gadgil, M. 1971. Dispersal: population consequences and evolution. Ecology 52:253-261.

Golani, I., and A. Keller. 1975. A longitudinal field study of the behavior of a pair of golden jackals. Pages 303-335 in M. W. Fox, et al. The wild canids. Van Nostrand Reinhold, New York.

Goss-Custard, J. D., R.I. M. Dunbar, and F. P. G. Aldrich-Blake. 1972. Survival, mating and rearing strategies in the evolution of primate social structure. Folia Primatologica 17:1-19.

Harper, L. V. 1970. Ontogenetic and phylogenetic functions of the parent-offspring relationship in mammals. Advance. Stud. Behav. 3:75-117.

Healey, M. C. 1967. Aggression and self-regulation of population size in deermice. Ecology 48:377-392. 
Hilborn, R. 1975. Similarities in dispersal tendency among siblings in four species of voles (Microtus). Ecology 56:1221-1225.

Howard, W. E. 1960. Innate and environmental dispersal of individual vertebrates. Amer. Midland Natur. 63:152-161.

Johnston, R. F. 1961. Population movements of birds. Condor 63:386-389.

Jolly, A. 1972. The evolution of primate behavior. Macmillan, New York. 397 pp.

King, J. A. 1955. Social behavior, social organization and population dynamics in a black-tailed prairie dog town in the Black Hills of South Dakota. Contrib. Lab. Vertebrate Bioi. Univ. Michigan 48:1123.

1973. The ecology of aggressive behavior. Annu. Rev. Ecol. Syst. 4:117-138.

Kleiman, D. G., and J. G. Eisenberg. 1973. Comparisons of canid and felid social systems form an evolutionary perspective. Anim. Behav. 21:637-659.

Knight, S. W. 1976. Dominance hierarchies of coyote litters. Paper presented at the meetings of the Animal Behavior Society, Boulder, Colo.

Kozakiewicz, M. 1976. Migratory tendencies in populations of bank voles and description of migrants. Acta Theriologica 21:321-338.

Krebs, C. J., M. S. Gaines, B. L. Keller, J. H. Myers, and R. H. Tamarin. 1973. Population cycles in small rodents. Science 179:35-41.

Krebs, C. J., I. Wingate, J. DeLuc, J. A. Redfield, M. Taitt, and R. Hilborn. 1976. Microtus population biology: dispersal in fluctuating populations of $M$. townsendii. Can. J. Zool. 54: 79-95.

Kruuk, H. 1972. The spotted hyena. University of Chicago Press, Chicago. 335 pp.

van Lawick-Goodall, H., and J. van Lawick-Goodall. 1970. Innocent killers. Houghton Mifflin, Boston. 222 pp.

Lidicker, W. Z. 1962. Emigration as a possible mechanism permitting the regulation of population density below carrying capacity. Amer. Natur. 96:29-33.

--- 1975. The role of dispersal in the demography of small mammals. Pages 104-120 in F. B. Galley, K. Petrusewicz, and L. Ryszkowski, eds. Small mammals: their productivity and population dynamics. Cambridge University Press, New York.

Lockwood, R. 1976. An ethological analysis of social structure and affiliation in captive wolves (Canis lupus). Ph.D. diss. Washington University. 362 pp.

McClenaghan, J. R., and M.S. Gaines. 1976. Density-dependent dispersal in Sigmodon: a critique. J. Mammal. 57:758-759.

Mech, L. D. 1970. The wolf. Natural History, New York. 383 pp.

van der Merwe, N.J. 1953. The jackal. Fauna and Flora 4:4-77.

Michener, G. R. 1973. Intraspecific aggression and social organization in ground squirrels. J. Mammal. 54:1001-1003.

Montgomery, G. G. 1974. Communication in red fox dyads: a computer simulation. Smithsonian Contrib. Zool. No. 187.

Murray, B. G. 1967. Dispersal in vertebrates. Ecology 48:97 5-987.

Myers, J. H., and C. J. Krebs. 1971. Genetic, behavioral and reproductive attributes of dispersing field voles Microtus pennsylvanicus and Microtus ochrogaster. Ecol. Monogr. 41:53-78.

1974. Population cycles in rodents. Sci. Amer. 230:38-46.

Mykytowycz, R. 1974. Odor in the spacing behavior of mammals. Pages 327-343 in M. C. Birch, ed. Pheromones. American Elsevier, New York.

Peters, R. P., and L. D. Mech. 1975. Scent-marking in wolves. Amer. Sci. 63:628-637.

van der Pijl, L. 1969. Principles of higher plant dispersal. Springer-Verlag, New York. 154 pp.

Preston, E. M. 1975. Home range defense in the red fox, Vulpes vulpes. J. Mammal. 56: 645-652.

Rose, R. K., and M.S. Gaines. 1976. Levels of aggression in fluctuating populations of the prairie vole, Microtus ochrogaster, in eastern Kansas. J. Mammal. 57:43-57. 
Rowell, T. E. 1974. The concept of dominance. Behav. Bioi. 11: 131-154.

Schaller, G. B. 1972. The Serengeti lion. University of Chicago Press, Chicago. 480 pp.

Scott, J. P., and J. L. Fuller. 1965. Genetics and social behavior of the clog. University of Chicago Press, Chicago. $468 \mathrm{pp}$.

Slade, N. A., and D. F. Balph. 1974. Population ecology of Uinta ground squirrels. Ecology 55: 989-1003.

Sohn, J. J. 1977. Socially induced inhibition of genetically determined maturation in the platyfish, Xiphophorus maculatus. Science 195:199-201.

Steiner, A. L. 1972. Mortality resulting from intraspecific fighting in some ground squirrel populations. J. Mammal. 53:601-603.

Storm, G. L. 1972. Population dynamics of reel foxes in the north central United States. Ph.D. diss. University of Minnesota. $227 \mathrm{pp}$.

Storm, G. L., and G. G. Montogomery. 1975. Dispersal and social contact among red foxes: results from telemetry and computer simulation. Pages 237-246 in M. W. Fox, et al. The wild canids. Van Nostrand Reinhold, New York.

Storm, G. L., R. D. Andrews, R. L. Phillips, R. A. Bishop, D. B. Siniff, and J. R. Tester. 1976. Morphology, reproduction, dispersal, and mortality of midwestern reel fox populations. Wildlife Monogr. 49:182.

Svensden, G. E. 1974. Behavioral and environmental factors in the spatial distribution and population dynamics of a yellow-bellied marmot population. Ecology 55:760-771.

Svensden, G. E., and K. B. Armitage. 1973. Mirror-image stimulation applied to field behavioral studies. Ecology 54: 623-627.

Trivers, R. 1974. Parent-offspring conflict. Amer. Zool. 14:249-264.

Vincent, R. E. 1958. Observations of reel fox behavior. Ecology 39:755-757.

Wandrey, R. 1975. Contribution to the study of social behaviour of captive golden jackals (Canis aureus L.). Z. Tierpsychol. 39:365-402.

Wilson, E. O. 1975. Sociobiology: the new synthesis. Harvard University Press, Cambridge, Mass. 697 pp.

Wilson, S. 1973. The development of social behaviour in the vole (Microtus agrestis). Zool. J. Linn. Soc. 52:45-62.

Windberg, L. A., and L. B. Keith. 1976. Experimental analyses of dispersal in snowshoe hare populations. Can. J. Zool. 54:2061-2081.

Yeaton, R. I. 1972. Social behavior and social organization in Richardson's ground squirrel (Spermophilus richardsonii) in Saskatchewan. J. Mammal. 53:139-147.

Zimen, E. 1975. Social dynamics of the wolf pack. Pages 336-363 in M. W. Fox, eel. The wild canids, Van Nostrand Reinhold, New York.

---. 1976. On the regulation of pack size in wolves. Z. Tierpsychol. 40:300-341. 